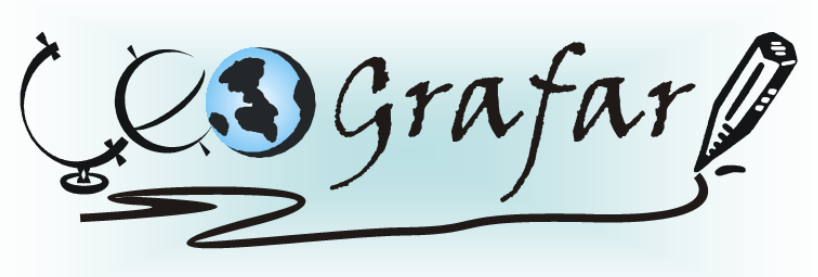

Revista Eletrônica do Programa de Pós-Graduação em Geografia - UFPR

\title{
TRAJETÓRIA DE VIDA DOS REASSENTADOS DA USINA HIDRELÉTRICA DE IRAPÉ NO VALE DO JEQUITINHONHA - MINAS GERAIS
}

\section{TRAJECTORY OF LIVES OF RESETTLED OF IRAPÉ POWER PLANT IN VALE DO JEQUITINHONHA - MINAS GERAIS}

\author{
Gilmar Fialho de Freitas \\ Mestrando em Geografia \\ Universidade Federal de Viçosa \\ Viçosa, MG, Brasil \\ e-mail:gilmarffreitas@yahoo.com.br \\ Marcelo Leles Romarco de Oliveira \\ Prof. Dr. do Departamento de Economia Rural \\ Universidade Federal de Viçosa \\ Viçosa, MG, Brasil \\ e-mail:mlromarco@yahoo.com.br \\ Bruno Costa da Fonseca \\ Graduando em Bacharelado em Cooperativismo \\ Universidade Federal de Viçosa \\ Viçosa, MG, Brasil \\ e-mail: bruno_fonsecacosta@hotmail.com
}

\section{RESUMO}

A concretização dos grandes projetos hidrelétricos no Brasil traz à tona uma discussão fundada na dualidade entre as partes envolvidas no processo: de um lado os empreendedores, dotados de um discurso desenvolvimentista voltado às demandas de uma sociedade industrializada; e do outro as populações rurais atingidas, que compulsoriamente são deslocadas para um reassentamento. Sendo assim, este estudo buscou entender como estão estruturadas as relações sociais desses segmentos afetados, de suas estratégias adaptativas em articulação com o 
território que atualmente ocupam, como também do universo de valores que dão sentido a estas relações. A partir desta constatação, este artigo tem por objetivo conhecer a trajetória de vida dos reassentados da Usina Hidrelétrica de Irapé no Vale do Jequitinhonha, desde os locais de origem até o atual momento em que residem nos reassentamentos. Para isso, utilizamos como procedimentos metodológicos tanto técnicas quantitativas quanto qualitativas, em que o método principal escolhido foi o estudo de caso, com uma amostra de 61 reassentados distribuídos em 10 associações diferentes, em 5 municípios da região: Turmalina, Leme do Prado, José Gonçalves de Minas, Capelinha, e Água Boa. Através deste estudo, constatamos que a trajetória de vida dessas populações que são reassentadas é marcada pela inevitabilidade que um processo de reassentamento forçado possui, e que estes estão, constantemente, imersos em um processo de mudança e de re-significação dos seus meios de vida.

Palavras Chaves: Trajetória, Vale do Jequitinhonha, reassentados, meios de vida

\begin{abstract}
The implementation of large hydropower projects in Brazil brings up a discussion based on the duality between the parties involved in the process on the one hand entrepreneurs endowed with a speech developmental facing the demands of an industrialized society, and the other rural populations affected, which are compulsorily displaced for resettlement. Therefore, this study sought to understand how social relations are structured these segments affected, their adaptive strategies in conjunction with the territory that currently occupy, but also the universe of values that give meaning to these relationships. From this finding, this paper aims to understand the trajectory of lives of resettled Irapé Power Plant in Vale do Jequitinhonha, from the places of origin to the present time residing in resettlement. For this, we use as instruments both quantitative and qualitative techniques, in which the main method chosen was the case study, with a sample of 61 resettled distributed in 10 different associations in five municipalities in the region: Turmalina, Leme do Prado, José Gonçalves de Minas, Capelinha, and Água Boa. Through this study, we could realize that the life histories of these populations which are resettled is marked by inevitability that a process of forced resettlement has, and they are constantly immersed in a process of change and re-signification of their livelihoods.
\end{abstract}

Keywords: Trajectory, Vale do Jequitinhonha, resettled, livelihoods

\title{
1 INTRODUÇÃO
}

A construção das grandes barragens, assim como outros grandes obras de infraestrutura, passam pela justificativa, ou mesmo por uma promessa, de apoio ao desenvolvimento e progresso da região aonde os empreendimentos são projetados 
e implantados. Os argumentos mais comuns que podem ser observados são de que esses investimentos se fundamentam em: novas oportunidades de emprego que são gerados, na dinamização da economia local, na melhoria da infraestrutura disponibilizada à população, entre outros. Estes seriam classificados como os impactos positivos da construção das grandes barragens, levando-se em conta a perspectiva de seus apoiadores.

Esta abordagem, portanto, não deve servir como referência quando tratamos das diversas comunidades rurais que são atingidas, direta e indiretamente, por esses empreendimentos. É preciso enxergar quão grande são as dificuldades dos reassentados em reproduzir suas vidas sob novas bases materiais e organizacionais, especialmente longe da água, elemento fundamental para o sucesso de suas atividades produtivas e referencial simbólico máximo de espacialidade. Um discurso desenvolvimentista e territorializador que vem dos interessados na construção de grandes empreendimentos hidrelétricos se choca com uma realidade sensível e sócio-culturalmente construída ao longo da vida dos ribeirinhos, o que revela as profundas irracionalidades e injustiças cometidas quando o que está em jogo é a imposição e não o diálogo.

De acordo com esta perspectiva, Ribeiro e Galizone (2003) ao estudarem a questão da água, as políticas de gestão e a população rural do Vale do Jequitinhonha em Minas Gerais, apontam que apesar da aplicação de esforços e recursos públicos necessários ao desenvolvimento do campo, grande parte da população rural permaneceu, e permanece, à margem da produção intensiva, dos mercados e até mesmo das discussões que envolvem o direcionamento de ações que lhes contemplem melhores condições de vida.

Num primeiro momento, Ribeiro e Galizone (2003) apresentam a ideia de que elaborar e transmitir conhecimentos é uma atividade permanente para estas populações rurais, pois a sua produção de alimentos e outros bens baseiam-se em suas práticas. Por essa razão, o território e suas formas sociais de apropriação têm para essa população uma enorme importância e uma forte valorização subjetiva. No caso específico apresentado sobre o Vale do Jequitinhonha, as nascentes e os pequenos cursos d'água são fatores fundamentais para a localização dessas populações, assim como da organização de suas atividades sociais e econômicas. 
Portanto, a construção da Usina Hidrelétrica Presidente Juscelino Kubitschek no Vale do Jequitinhonha, mais conhecida como Usina de Irapé, pertencente à Companhia Energética do Estado de Minas Gerais (CEMIG), ocasionou uma mudança profunda nos meios de vida de seus atingidos, que somam mais de mil famílias ribeirinhas. Registros apontam que 47 comunidades, em áreas dos municípios mineiros de Berilo, José Gonçalves de Minas, Leme do Prado, Turmalina, Grão Mogol, Cristália e Botumirim, foram afetadas e deslocadas de suas terras.

Nesse sentido, a construção da Usina Hidrelétrica de Irapé, impôs às famílias atingidas, uma mudança compulsória de seus meios de vida. Diante desse panorama, é importante ressaltar que as comunidades atingidas possuíam formas diferenciadas de relações sociais, culturais, econômicas e territoriais que dificilmente poderão ser reaplicadas em outra localidade, ou seja, observa-se a tentativa de homogeneização da diversidade sociocultural das comunidades

Assim sendo, este trabalho tem como objetivo entender e analisar a trajetória de vida dos atingidos da Usina Hidrelétrica de Irapé, destacando inicialmente como contexto de análise, como era a vida destes ribeirinhos em suas comunidades de origem, destacando a estruturação de suas vidas de acordo com as condições econômicas, sociais e ambientais em que viviam. Em seguida procuramos conhecer como foi construída a ideia da necessidade de abandonarem suas antigas localidades para irem para um reassentamento, e também de entender como se deu este processo. Por fim, apresentamos o contexto atual de vida dessas famílias nos seus respectivos reassentamentos, buscando apresentar os pontos positivos e negativos desse novo estilo de vida em comparação com as condições anteriores.

\section{MATERIAL E MÉTODOS}

A pesquisa foi desenvolvida utilizando-se tanto de técnicas qualitativas como quantitativas. Esse tipo de estudo é justificado, sobretudo, pela valorização do produto final do trabalho que esses dois tipos de reflexão podem trazer. Conforme analisa Gobo (2005), as vantagens de estudos que conciliam as duas abordagens têm garantido maior grau de formalização, ou seja, se inscrevem no âmbito de estudos que adotam um método reflexivo. Segundo o mesmo autor, "[...] a atividade de formalizar convida o pesquisador a explicitar os seus argumentos, as instituições 
e os conhecimentos tácitos, a fim de fornecer aos leitores as informações para um diálogo no interior da comunidade científica" (p.92).

O método utilizado neste trabalho se trata do estudo de caso. Este se caracteriza como um tipo de pesquisa cujo objeto é uma unidade social que se analisa profundamente. Visa o exame detalhado de um ambiente, neste caso rural. Tem por objetivo, também, proporcionar vivência da realidade por meio da análise e tentativa de solução para um problema extraído da vida real. O estudo de caso tem se tornado a estratégia preferida quando os pesquisadores procuram responder às questões "como" e "por que" certos fenômenos ocorrem. Adotando um enfoque exploratório e descritivo, o pesquisador que pretende desenvolver um estudo de caso deverá estar aberto às suas descobertas, utilizando uma variedade de dados coletados por meio de variadas fontes de informação. O principal objetivo de um estudo de caso é, segundo Godoy (1995), aprofundar a descrição de um determinado fenômeno.

Os dados coletados em cada território de investigação foram de fundamental valia para dar conta do desafio de juntar os pedaços - das diversas dinâmicas analisadas - para entender e localizar às áreas rurais que constituíram a base deste estudo, compreendidos aqui como espaços históricos, políticos, social, econômico e culturalmente instituídos e instituidores de identidades.

Destarte, buscamos inspiração no ponto de vista idiográfico que, segundo analisa Rebughini (2005), é "[...] utilizada em antropologia e em etnologia, mas sempre mais frequente também na sociologia" (p.244). Ainda segundo o autor, no âmbito da comparação idiográfica, procede-se, primeiro, uma investigação sobre como se formam e se expressam determinados fenômenos, em cada um dos contextos a serem comparados para, em seguida, se buscar possíveis relações entre esses aspectos. A comparação, porém, tal como adverte Rebughini (2005), "[...] não deve ser nunca entendida como método de controle das hipóteses [...]" e, sim, "[...] como técnica para melhor compreender, descrever e explicar os fenômenos observados e comparados" (p. 246).

Portanto, considerando que, à exceção de oito famílias que residiam na área atingida do município de Berilo que optaram pela venda de suas propriedades, as demais 122 famílias residentes em áreas rurais dos municípios de José Gonçalves 
de Minas, Leme do Prado, Capelinha, Água Boa e Turmalina, foram remanejadas e reassentadas.

Desse universo, participaram do estudo 61 titulares de lotes, chefes de famílias, organizados em dez Associações de Moradores dos Reassentamentos situados nos cinco já referidos municípios. A seguir, apresentamos um quadro detalhando o universo da pesquisa, destacando os municípios e suas respectivas associações que foram selecionadas, assim como apresento o número de famílias que foram reassentadas nas associações e as famílias que foram selecionadas para este estudo:

Tabela 1: O universo de pesquisa

\begin{tabular}{|c|c|c|c|}
\hline Municípios & Associações Selecionadas & № de Famílias Reassentadas & № de Famílias selecionadas \\
\hline José Gonçalves de Minas & $\begin{array}{l}\text { Coração de Maria e União de } \\
\text { Todos }\end{array}$ & 29 Famílias & 18 Famílias \\
\hline Leme do Prado & $\begin{array}{l}\text { Quilombo Boa Sorte, Coração de } \\
\text { Jesus e Mandassaia }\end{array}$ & 40 Famílias & 17 Famílias \\
\hline Turmalina & Povoado Peixe Cru & 22 Famílias & 11 Famílias \\
\hline Capelinha & $\begin{array}{l}\text { Fartura, São Caetano e Santa } \\
\text { Bárbara }\end{array}$ & 19 Famílias & 7 Famílias \\
\hline Água Boa & $\begin{array}{l}\text { Novo Horizonte e Ribeirão } \\
\text { Vermelho }\end{array}$ & 14 Famílias & 8 Famílias \\
\hline Total & 11 Associações & 124 Famílias & 61 Famílias \\
\hline
\end{tabular}

Fonte: Dados da pesquisa, 2010

Direcionamos, ainda, aos titulares dos lotes, um questionário composto de questões objetivas relativas às seguintes dimensões: econômica, social, cultural, de infraestrutura, e de produção, com a finalidade de caracterizar tanto os participantes como seus contextos anteriores e atuais de vida.

\section{RESULTADOS}

\section{1 - A vida à beira do rio (local de origem)}

Nesse momento de nossa reflexão, tivemos como objetivo conhecer a vida dos reassentados na época em que moravam à beira do Rio Jequitinhonha, ou seja, conhecer seus hábitos, costumes e sua forma de viver. Como era a relação com os 
parentes, vizinhos, com a terra, com o rio, as formas de produção e as descrições do local de origem.

A grande maioria dos reassentados moravam na região de origem desde que nasceram, seguindo o exemplo de seus pais. Esse fato nos chama a atenção para a maior probabilidade da existência de um espaço de relações bem formadas ao longo dos anos. Soma-se a isso o vínculo com os elementos da paisagem e os vínculos sociais bem estruturados entre as pessoas e nas formas de expressão das culturas e práticas religiosas, que na maioria das vezes foram herdadas ao longo dos anos. Essa questão é demonstrada através da Tabela 2:

Tabela 2 - Tempo que residia na propriedade de origem

\begin{tabular}{cc}
\hline Tempo que residia na propriedade de origem & $\%$ \\
\hline Um ano & $0,00 \%$ \\
Até 5 anos & $3,27 \%$ \\
Até 10 anos & $4,92 \%$ \\
Até 20 anos & $6,55 \%$ \\
Mais de 20 anos & $81,99 \%$ \\
Não se aplica & $3,27 \%$ \\
\hline
\end{tabular}

Fonte: Dados da pesquisa, 2010

Em relação ao tempo de residência na propriedade de origem, verificou-se que $3,27 \%$ moravam na área atingida pela barragem de um a cinco anos; 4,91\% entre cinco e dez anos; 6,55\% entre dez e vinte anos; e 82,00\% há mais de vinte anos, revelando assim que a grande maioria era morador antigo na região. Esta situação indica também a dificuldade dessas famílias em deixar tudo que construíram, sejam bens materiais ou simbólicos, para, forçosamente, recomeçarem a vida em um lugar estranho.

O trabalho da grande maioria dos reassentados em seus locais de origem girava em torno da obtenção dos alimentos necessários para o sustento da família, podendo incluir a venda de excedentes em determinadas situações. Conforme afirma Wanderley (2009) um dos aspectos relevante sobre o camponês e sua forma de produzir diz respeito à natureza da produção que é posta a venda. Esta produção não se trata de um excedente que sempre é produzido na perspectiva de ir além a 
sua reprodução e de sua família, e sim um complemento aos seus meios de vida e de obtenção de instrumentos para o trabalho. Na produção camponesa não há a escolha por plantar para vender ou para o sustento, a troca do excedente realizada no mercado é uma alternativa para a garantia de condições mínimas de sua reprodução.

Boa parte dos homens, pais de família, também trabalhavam a dia de serviços para aqueles que demandassem, como no caso das plantações de eucalipto que prevalecem na região. A maioria dos reassentados começaram a trabalhar muito cedo para a ajudar nas necessidades da casa. De acordo com Candido (2003, p. 31):

\begin{abstract}
Este modo de produção não deve ser considerado apenas como reprodução da existência física dos indivíduos, ele já é uma espécie determinada da atividade destes indivíduos, uma determinada maneira de manifestar a sua vida, uma determinada maneira de viver destes indivíduos [...]
\end{abstract}

Conforme analisa Sposito (2010) uma possibilidade observada para caracterizar os espaços se trata do modo de vida que seus habitantes ocupam num determinado contexto histórico. A vida rural ainda é muito dependente da valorização da vida comunitária, onde boa parte de seus comportamentos são regidos por relações de parentesco e vizinhança, e por influência de sua religiosidade.

Contudo, a questão da produção era extremamente limitada ao consumo da família, já que o acesso à cidade era muito difícil e a condição financeira das famílias não permitia outra forma de consumo, como por exemplo, o uso de produtos industrializados. A casa do ribeirinho recebia uma produção bastante diversificada, como: milho, feijão, mandioca, batata, frutas e hortaliças. De acordo com Heredia (1979, p. $77-78)$ :

Os produtos fornecidos pelo roçado são os que asseguram o abastecimento dos meios necessários para o consumo familiar, consumo que se materializa na casa. Consequentemente, é o roçado que dá condições de existência à casa como local de consumo [...] 
No caso da profissão dos reassentados em seus locais de origem, esta ficava restrita ao roçado para os homens com ajuda das mulheres quando necessário, principalmente no plantio e na colheita em que a necessidade de mão de obra era maior, e estas se dedicavam ainda as atividades da casa, cuidar dos filhos e das hortas de quintal. Nestes termos, o trabalho da mulher é apenas reconhecido como ajuda e não como uma profissão. $O$ trabalho de Heredia (1979) também destaca o papel da mulher no roçado e como esta é vista:

Por outro lado, as atividades da casa, por estarem ligadas ao consumo, não são consideradas como trabalho e correspondem à esfera de domínio feminino. O campo de ação da mulher é a casa e, por consequência, considera-se que esta não trabalha. Sem dúvida, muitas vezes, como já pudemos observar, as mulheres desenvolvem tarefas no roçado; além do mais, dentro das atividades próprias ao roçado, a semeadura é uma atividade considerada feminina e é realizada exclusivamente por mulheres. Além disso, cabe a elas outro tipo de tarefas, como por exemplo as limpezas periódicas que os cultivos requerem depois de serem plantados, embora homens e crianças também participem desta atividade (HEREDIA, 1979, p. 80)

É muito comum na região trabalhos à meia ou com outro tipo de parceria, assim como era muito frequente as trocas de dias. Essas práticas ainda são frequente nos reassentamentos, mas em grau inferior. Outro ponto de destaque é que a questão da incidência de outras fontes de renda é muito pequena, aonde apenas algumas famílias produzem alguns produtos como doces e conservas para o mercado dos municípios (produção individualizada), e alguns relatos de produção de panelas de pedras, ou algumas pessoas que trabalhavam aonde se produziam as peças.

\section{2 - A construção da hidrelétrica - Etapas do reassentamento}

Com a definição de que as obras da UHE Irapé deveriam começar, após a obtenção das licenças necessárias, iniciou-se as etapas do reassentamento das famílias que seriam atingidas. Primeiramente, buscou-se identificar junto aos reassentados como foi formada a ideia sobre a necessidade de sair de seu local de origem para o reassentamento. Conforme os relatos, foi formada dentro de um ambiente de muita expectativa por parte das famílias reassentadas. A ideia principal 
que moveu as famílias pelo acordo da necessidade de relocação perpassou pela esperança de construção de uma vida melhor, principalmente quando se relaciona a expectativas de maiores oportunidades para os filhos, de estudo e emprego.

Em Durkheim e Mauss (2001), evidencia-se então que a diversidade dos elementos são formados por mecanismos, do qual construímos, projetamos e localizamos em um determinado espaço nossas representações do mundo sensível. Portanto, se torna visível as classificações que atribuímos às coisas e indivíduos, tendo por pressuposto a busca por uma ordenação em grupos distintos, aonde suas demarcações sejam evidentes e determináveis. As especificidades das relações anteriormente destacadas situam-se dentro de um espaço que é determinado e que verdadeiramente faz parte da vida de seus habitantes.

Munidos por esta forma de representação do espaço a ser concebido, o primeiro contato "formal" com a ideia de ser reassentado, foi através de reuniões proporcionadas pela CEMIG nas comunidades atingidas, tendo em vista que no momento das reuniões o órgão empreendedor já chegava munido de todas as informações necessárias que foram elaborados através de estudos contratados pela empresa. Na verdade, a ideia começou a aparecer através dos boatos e mesmo a partir de pessoas estranhas que chegavam à região. Esses sempre causavam grande estranhamento. Através dos relatos, fica bem evidente que todas as questões envolvidas na relocação eram tratados com bastante detalhe nas reuniões, mas é bastante instigante se era acessível aos reassentados a compreensão dos fatos, já que suas expectativas poderiam estar acima dos questionamentos.

No caso das comunidades que foram formadas no estilo de agrovilas as famílias afirmavam que imaginavam como seriam formados os reassentamentos, e também disseram que realmente foi como imaginavam, com apenas alguns detalhes de variações. Neste caso, associa-se ao fato de que a CEMIG ressaltava sempre que as comunidades sofreriam o mínimo de mudanças em sua forma, apenas incluindo alguns elementos tipicamente urbanos, como: água encanada, calçamento e iluminação pública. A seguir observa-se uma foto tirada em uma das mais tradicionais comunidades que foram reassentadas, a Comunidade de Peixe Cru no município de Turmalina-MG, que vem justamente para ilustrar o estilo de agrovilas utilizados nos reassentamentos. 


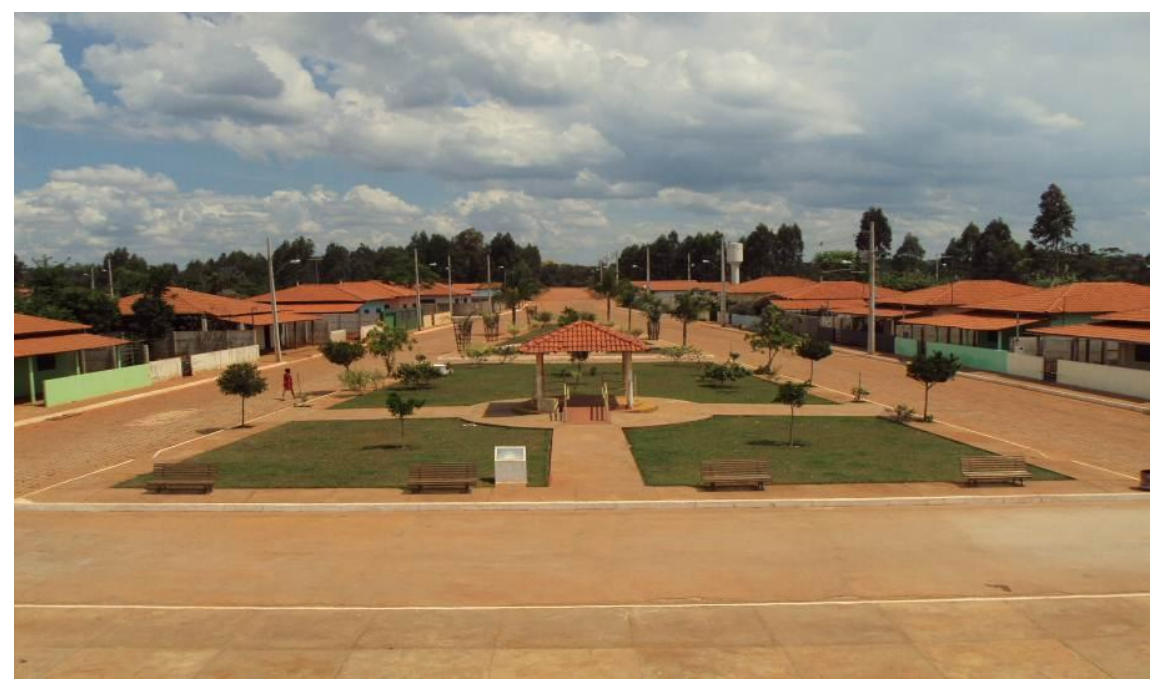

Figura 1: Povoado de Peixe Cru, em Turmalina - MG.

Fonte: fotos dos autores, 2010

Já nas associações formadas com as famílias dispersas em seus lotes, aonde se observa uma maior distância entre as casas, é evidente a reclamação sobre isolamento e pouca relação entre as mesmas. A mudança neste caso foi maior, justificando a afirmação dos reassentados de que imaginavam que os reassentamentos fossem diferentes, ou mesmo não chegaram a medir as consequências do distanciamento entre os vizinhos. Os relatos quase sempre evidenciavam que nos locais de origem a proximidade, tanto geográfica como afetiva entre a vizinhança, era maior.

Os estudos e debates relacionados ao processo das construções das grandes hidrelétricas, tende em sua maioria, infelizmente, a promover a redução da diversidade sociocultural e a simplificar sua complexa organização social e territorial. De acordo com os estudos de Vainer (1993, p.564), os discursos "oficiais" que prestam serviço ao lado empreendedorista das negociações:

[...] vêm sempre na voz passiva, a expressar sua objetivação num discurso globalmente fundado na naturalização da vida social: assim, temos: populações afetadas, atingidas, impactadas, deslocadas, remanejadas, preservadas, reassentadas, sempre passivas, inexoravelmente condenadas a ser campo de ação de um outro, meio ambiente impactado pela intervenção do empreendedor/empreendimento hidrelétrico. 
Tendo em vista a complexidade do processo, uma das primeiras etapas que compreenderam o processo de reassentamento dos atingidos pela Usina Presidente JK foi a seleção das terras para onde seriam relocadas essas famílias. Em seguida começaram as escolhas dos lotes por parte dos reassentados. As famílias deveriam escolher suas terras, se assim fosse de sua vontade, respeitando as proximidades que existiam no local de origem, a fim de que laços de vizinhança, amizade e parentesco se mantivesse na nova localidade.

A maior parte das terras escolhidas para formar os lotes para o reassentamento das famílias atingidas foram nas chapadas que circundam a área do reservatório formado pela barragem. Porém, registra-se casos de famílias que foram reassentadas a mais de $100 \mathrm{KM}$ da região de origem, como por exemplo alguns reassentamentos formados na áreas rurais de Capelinha e Água Boa. Nas agrovilas observou-se relatos de que as famílias puderam escolher a sua vizinhança, ou seja, escolhiam os lotes de acordo com quem estava reassentado ao lado, ou mesmo a formação de alguns grupos de famílias que a partir de então escolhiam seus lotes juntos.

A seguir apresenta-se algumas informações sobre a participação dos reassentados na escolha das terras aonde seriam demarcados os reassentamentos, bem como de sua participação na escolha do lote que atualmente reside:

Tabela 3 - Participação na Etapa de Seleção das Terras e dos lotes no Reassentamento

\begin{tabular}{ccc}
\hline Participação nas etapas & Participação na seleção das terras (\%) & Participação na seleção dos lotes (\%) \\
\hline Sim & $91,80 \%$ & $78,69 \%$ \\
Em parte & $3,28 \%$ & $9,84 \%$ \\
Não & $4,92 \%$ & $11,47 \%$ \\
\hline
\end{tabular}

Fonte: Dados da pesquisa, 2010

Através da Tabela 3, observa-se que a grande maioria dos reassentados $(91,80 \%)$ participaram da escolha das terras as quais seriam destinadas a formação dos reassentamentos. Assim como 78,69\% também afirmaram que puderam escolher seus respectivos lotes que atualmente ocupam. Através desses dados conclui-se que houve uma grande mobilização popular em torno de várias decisões importantes, como na situação apresentada anteriormente. A escolha das terras se deu de forma prevista no acordo e a população esteve no direito de escolher para 
quais "terras" iriam e onde seus lotes situariam. As terras do reassentamento foram repartidas seguindo os critérios e os tamanhos definidos pelo acordo. Durante essa etapa buscou-se preservar as proximidades e os laços afetivos existentes entre as famílias na comunidade de origem, a fim de que permanecessem próximos na nova localidade e para que a adaptação se desse de uma maneira menos impactante possível.

Antes das definições referentes às distribuição das terras e dos lotes era preciso que fosse feita uma avaliação prévia de benfeitorias do lote de origem, para que o reassentado fosse indenizado de acordo com os bens que possuía. Uma das modalidades aplicada quanto a forma de ressarcimento aos reassentados sobre as perdas que teriam com o abandonar de suas terras de origem, se deu através de indenizações monetárias.

Portanto, as informações apresentadas a seguir demonstra a opinião dos reassentados se realmente foram indenizados, assim como estava previsto no acordo de realocação:

Tabela 4 - Pagamento de Indenizações aos Reassentados

\begin{tabular}{cc}
\hline Pagamento de Indenizações & $\%$ \\
\hline Foi Indenizado & $73,77 \%$ \\
Foi Indenizado Parcialmente & $13,12 \%$ \\
Não Foi Indenizado & $9,84 \%$
\end{tabular}

Fonte: Dados da pesquisa, 2010

Através da Tabela 4, observa-se que $86,89 \%$ dos entrevistados afirmaram ter recebido as indenizações, sendo que 73,77\% disseram que a indenização se deu de forma integral e apenas 13,12\% afirmaram que estas se deram parcialmente. Somente uma pequena parcela de 9,84\% dos entrevistados afirmaram não terem sido indenizados. O não pagamento de indenizações a algumas famílias deve-se, basicamente, ao não enquadramento às proposições elaboradas pela CEMIG, ou seja, algumas famílias não possuíam benfeitorias na região de origem ou mesmo porque moravam com outras famílias.

Portanto, as benfeitorias que os reassentados possuíam em seus locais de origem foram descritas como bem avaliadas, o que refletiu nas indenizações monetárias recebidas pelas famílias. A maior parte dos pesquisados afirmaram ter 
sido justo aquilo que Ihes foi oferecido. Aqui destacamos com bastante ênfase o depoimento recolhido sobre a administração desses recursos por muitas famílias indenizadas. Em poucos casos, percebe-se famílias que souberam investir o seu dinheiro e estão melhorando sua condição financeira a cada dia. Por outro lado, observa-se relatos de famílias que não souberam coordenar seus gastos e hoje vivem em situações iguais ou piores às condições que ocupavam antes de serem reassentadas.

Nas palavras de Sigaud (1992) observa-se os efeitos perversos contidos nas políticas do setor elétrico, que são responsáveis pelo deslocamento compulsório e extremamente desorganizado de milhares de cidadãos brasileiros, contribuindo para seu empobrecimento e por uma profunda transformação do seu modo de vida.

Torna-se bastante comum na região a aquisição, por parte dos reassentados, de veículos automotores com o dinheiro pago pelas indenizações, sem medir as consequências dos possíveis gastos que o transporte pode trazer futuramente (manutenção). Destaca-se também outras formas de investimentos (equipamentos domésticos, de produção e outros) que muitas vezes estão subordinadas à pessoas de má fé, aproveitando o baixo grau de informação e escolaridade que há entre os reassentados. Evidencia-se com isso a falta de orientação dos órgãos responsáveis pelo empreendimento e reassentamento dos atingidos em, de alguma forma, orientar ou mesmo acompanhar a administração dos recursos por estas famílias. Fica bem evidente que os "indenizadores" pensam apenas em cumprir a meta de indenizar, conferindo às famílias a responsabilidade sobre seus investimentos.

Outra questão que destacamos com bastante ênfase se trata dos impactos socioculturais que o empreendimento trouxe para aquelas comunidades atingidas. Quando os primeiros interessados chegaram a região, no caso a empresa que avaliava o potencial energético do rio, perceberam que algumas medidas deveriam ser tomadas em relação ao rico acervo cultural que o Vale do Jequitinhonha possuía. Antes do processo de reassentamento, nas reuniões que eram realizadas para a definição de como as famílias atingidas seriam reassentadas, os reassentados afirmaram que estas questões em relação à preservação de seus costumes, cultura e práticas religiosas foram discutidas. Estes também afirmaram 
que os empreendedores diziam que "tudo no reassentamento, as festas e outras manifestações, seriam iguais como eram feitas no local de origem".

Houve alguns relatos de que a CEMIG contratou algumas pessoas para que fizessem o registro dessas manifestações, assim como no que diz respeito em relação ao patrimônio arqueológico, para serem reproduzidas nas atuais localidades. Aqui, portanto, chamamos a atenção para uma discussão difícil de ser realizada nessas reuniões, já que o tema é bastante subjetivo, ou mesmo, que as famílias atingidas não compreendessem a verdadeira dimensão do problema a ser gerado, ou também, que estivessem mais preocupadas com outros assuntos.

Nesse sentido, nos estudos de Santos (2007), desenvolveu-se uma reflexão muito relevante a se destacar sobre as implicações sociais das barragens, voltandose para uma dimensão que geralmente se torna bem negligenciada: o sofrimento e a dor dos expropriados,

[...] os relatos sobre o deslocamento compulsório evocam uma pluralidade de situações de transformação, traduzidas em perdas, que contemplam desde o espaço físico, o estranhamento da nova situação vivida até as relações cotidianas e de proximidade. Desta perspectiva, creio ser possível afirmar que, com a intervenção sobre o espaço físico para a formação do lago, atinge-se violentamente as relações sociais, desestruturando-as. É esta desestruturação que conforma o substrato do lamento e da dor. (SANTOS, 2007, P. 194)

É inegável que as comunidades atingidas por barragens possuíam formas diferenciadas de relações sociais, culturais, econômicas e territoriais que dificilmente poderão ser reaplicadas em outra realidade. Assim como também é fato a tendência de homogeneização da diversidade sociocultural das comunidades deslocadas.

\section{3 - A vida no reassentamento}

A vida dos reassentados em suas atuais localidades está estruturada em situações bem diversas, já que é nítido um tratamento diferenciado oferecido às comunidades atingidas. Só para ressaltar possíveis contentamentos e descontentamentos, observa-se que em comunidades mais distantes dos núcleos urbanos e com dispersão das famílias em seus respectivos lotes, os reassentados afirmaram que sua vida não anda tão bem, porém ressaltamos que nesta questão 
pode haver situações pessoais, familiares, ou mesmo de infraestrutura que justifique a opinião. Também é indiscutível, que a maioria das famílias que estão situadas nas agrovilas, se consideram satisfeitas com a sua vida aonde estão. De fato, como observado, muitos aspectos estruturais e de acesso a serviços necessários condicionam a sua opinião.

Conforme analisa Melucci (2001), é possível identificar diferenças entre as novas e velhas solidariedades, uma vez que as últimas se constituem em tempos de globalização e individualismo. $\mathrm{Na}$ acepção do autor, as velhas solidariedades eram aquelas que se baseavam muito na proximidade. Os vínculos se davam nas residências, nas vizinhanças, na família, no trabalho. E é isso que de alguma maneira tem se modificado, porque as relações agora estão mais distantes, a mobilidade espacial é maior, as migrações são mais intensas. Em todo o mundo está se criando uma deslocalização e, portanto, se criam novas raízes que de alguma maneira estavam criados nas comunidades tradicionais. Essas raízes comunitárias perderam-se e criou-se um problema, ou seja, as velhas solidariedades estão dando lugar ao individualismo.

Tão fundamental quanto falar das solidariedades é também ter em mente que, o que muitas vezes se busca é compreender a qualidade de vida de um determinado grupo. Conforme analisa Souza (1982, p.15), a qualidade de vida:

[...] abrange tanto a distribuição dos bens de cidadania - os bens e direitos que uma sociedade, em dado momento, julga serem essenciais - quanto a de uma série de bens coletivos de natureza menos tangível e nem por isso menos reais em suas repercussões sobre o bem-estar social.

Do ponto de vista da Organização das Nações Unidas (ONU), a qualidade de vida está relacionada a satisfação do cidadão, no que diz respeito ao acesso a alimentação, aos serviços de saúde, ao conhecimento, as boas condições de trabalho, ao lazer e a participação nas atividades econômicas, culturais e políticas da comunidade.

Neste estudo, também é bastante pertinente ressaltar que a felicidade de determinados grupos, como por exemplo a satisfação de parte dos atingidos em suas novas localidades, geralmente está associada a uma boa administração da família e dos recursos que ela dispõe, sobretudo aqueles que foram adquiridos 
através das indenizações. Ou seja, sempre é preciso evidenciar que é um conjunto de fatores que define a opinião em relação à determinados assuntos. Contudo, nesse momento destacamos a importância das descrições e observações sobre como está organizada a vida do reassentado nessas novas localizações, bem como as disposição das condições e serviços essenciais ao seu dia a dia.

A questão referente ao acesso à escola é bastante complicado. Um fato interessante é a inserção do transporte escolar na vida desses estudantes dos reassentamentos. Com a nucleação das escolas nos centros urbanos, ou a construção de unidades escolares apenas em aglomerados habitacionais, as Prefeituras e/ou Estado disponibilizam ônibus ou vans para o transporte dos alunos. Em tese, a escola estando localizada ou não próximo à residência familiar, os alunos em idade escolar não deveriam ficar sem estudar. A CEMIG não se responsabilizou pela construção de escolas, a não ser nas agrovilas, por considerar que a educação, assim como a saúde é de responsabilidade do Estado. Outro ponto importante a ser pensado se trata da questão da centralização das escolas em áreas urbanas ou em pequenos aglomerados, que de uma maneira ou de outra, pode dificultar a inserção desse aluno no seu contexto.

Tabela 5 - Acesso à escola na comunidade de origem e no reassentamento

\begin{tabular}{ccc}
\hline Acesso à escola & Local de origem (\%) & Reassentamento (\%) \\
\hline Próximo à residência & $60,65 \%$ & $44,26 \%$ \\
Distante da residência & $24,60 \%$ & $52,46 \%$ \\
Não tinha (tem) acesso à escola & $14,75 \%$ & $1,64 \%$ \\
Fonte: Dados da pesquisa, 2010 & &
\end{tabular}

$\mathrm{Na}$ propriedade de origem, uma grande parcela dos entrevistados (60,65\%) afirmaram que tinham acesso à escola com proximidade, isto é devido muitas vezes a um caráter mais informal que a educação assumia alguns anos atrás, onde existia uma grande subdivisão de escolas rurais, que funcionavam até mesmo em casas de algumas dessas famílias. Também é possível perceber o aumento de opiniões que revelam que as escolas ficaram mais distantes com o reassentamento $(52,46 \%)$, fato também que se relaciona a uma maior incidência de jovens que frequentam o ensino médio, que geralmente só é oferecido nas cidades. 
É indiscutível a maior oportunidade criada quando nos referimos ao acesso dos estudantes à escola após o reassentamento. Também obtivemos casos de pessoas (inclusive adultos) que estão voltando a estudar, e que manifestaram seu descontento com a dificuldade de acesso ao nível superior na região.

Com relação ao acesso aos postos de saúde, a CEMIG somente construiu nas agrovilas ou aglomerados urbanos. Outros casos identificados foram que alguns reassentamentos foram implantados nas vizinhanças de algum distrito ou aglomerado urbano que já possuíam postos de saúde antes da transferência das famílias. $O$ atendimento nos postos de saúde, à semelhança do que acontece em diversas regiões do país, é bastante precário, descontínuo e insuficiente. A disponibilidade de médicos é irregular e de enfermeiros também, e estas questões são focos de reclamações dos moradores da região.

Outra questão, não menos importante, se trata das possibilidades de lazer nos reassentamentos formados. A grande ausência de infraestrutura de lazer no meio rural é generalizada no Brasil como um todo, portanto, não seria diferente nos reassentamentos estudados. Atualmente, as principais atividades de lazer verificadas estão, especialmente, nas agrovilas, onde foram construídos campos de futebol, quadras poliesportivas, uma sede para a associação que serve para atividades sociais, igreja e, em um aglomerado urbano encontrou-se até uma piscina semi-olímpica. Nos demais lugares a regra geral é um precário campo de futebol e bares com mesas de sinuca. A seguir, através da Tabela 6 observa-se as opiniões dos reassentados sobre a disponibilidade de alguma forma de lazer nos reassentamentos em relação ao seus locais de origem:

Tabela 6 - Infraestrutura de lazer no local de origem e no reassentamento

\begin{tabular}{ccc}
\hline Infraestrutura de lazer & Local de origem (\%) & Reassentamento (\%) \\
\hline Havia/há & $44,26 \%$ & $14,75 \%$ \\
Havia/há parcialmente & $21,31 \%$ & $18,04 \%$ \\
Não havia/há & $34,43 \%$ & $65,57 \%$
\end{tabular}

Fonte: Dados da pesquisa, 2010

Mais de $65,57 \%$ dos reassentamentos não dispõem de qualquer área de lazer, especialmente para a juventude, o que dificulta e muito a manutenção dos 
filhos dos agricultores no meio rural. Alves Filho (2008), pesquisando assentamentos de reforma agrária do INCRA em Minas Gerais também encontrou esta mesma ausência de lazer para os filhos dos beneficiários da reforma agrária e se tornando uma das variáveis responsáveis pelo êxodo dos jovens do meio rural para a cidade, especialmente para aqueles que tiveram acesso a mais tempo à escola. Do outro lado, podemos observar que a maior parte dos pesquisados (65,57\%), afirmaram que dispunham desse ambiente em suas localidades de origem, mesmo que de maneira parcial. Essa referência, na maioria dos casos, condiz com as proximidades que as residências dos reassentados possuíam do rio, que foi citado em diversos momentos como a melhor alternativa de lazer que essa população desfrutava na sua região de origem.

Outra questão que este estudo se ateve diz respeito ao abastecimento de água às famílias reassentadas. A maioria destas afirmaram utilizar atualmente como fonte principal as redes de distribuição de água dos reassentamentos, o que tem gerado bastante descontentamento entre alguns reassentados. A questão negativa apresentada, se deve ao fato que grande parte dessas famílias possuíam facilidade de acesso à água no local de origem, pois moravam à beira do rio, e atualmente a disponibilidade de água é controlada pela distribuição encanada, assim como é feito nas cidades, o que tem gerado inúmeras discussões. Também é importante ressaltar a construção de reservatórios de água da chuva, para que o assentado também possua água para outras finalidades durante os períodos de seca. No atual momento, ressaltando a visita dos pesquisadores aos reassentamentos em agosto de 2012, também repercute-se a possível implantação de cobrança sobre a distribuição da água encanada, ou seja, os reassentados em breve vão estar pagando pela água utilizada. 
Tabela 7 - Fonte de abastecimento de água utilizada na propriedade de origem e no reassentamento

\begin{tabular}{ccc}
\hline Fonte de abastecimento de água & Local de origem (\%) & Reassentamento (\%) \\
\hline Rede & $22,95 \%$ & $73,76 \%$ \\
Rio & $39,35 \%$ & $1,64 \%$ \\
Poço & $3,28 \%$ & $13,12 \%$ \\
Mina/Fonte & $18,03 \%$ & $4,92 \%$ \\
Outras & $16,39 \%$ & $4,92 \%$ \\
Não se aplica & $0,00 \%$ & $1,64 \%$ \\
\hline
\end{tabular}

Fonte: Dados da pesquisa, 2010

A Tabela 7, apresentam os dados referentes à fonte de abastecimento de água que é e foi utilizada pelos assentados no reassentamento e na propriedade de origem. A maioria (73,76\%) dos entrevistados afirmaram utilizar atualmente como fonte as redes de distribuição de água dos reassentamentos. Já no local de origem, $39,35 \%$ dessas famílias utilizavam as águas do rio, prática que era comum para essa população caracterizada como ribeirinha. Também era bastante comum o uso de minas ou fontes, destacado por $18,03 \%$ dos entrevistados, e menos relevante 0 uso de poços em 3,28\% dos casos pesquisados. Os dados apresentados demonstram a grande mudança sofrida na vida dos reassentados em relação a este bem natural indispensável à vida dos seres humanos, pois o que antes era abundante hoje é controlado pelas torneiras.

A água nos reassentamentos não é utilizada somente para o consumo humano, mas também para os animais domésticos e para o cultivo das terras. A partir de então, buscou-se conhecer as considerações dos reassentados sobre as terras dos reassentamentos. Podemos observar que há um equilíbrio entre as opiniões de que são boas ou ruins, isso se dá devido basicamente aos lugares físicos onde essas famílias foram reassentadas, ou seja, algumas famílias foram reassentadas longe da propriedade de origem, que em sua quase totalidade era pertencente a uma área semiárida, para regiões de transição com a faixa norte da Zona da Mata Mineira, de clima mais ameno e com solos mais férteis. As famílias que se mantiveram mais próximas de sua região de origem foram, em sua maioria, 
as que afirmaram ter decaído as condições de produção, sobretudo pela falta de água.

Quando questionamos o nível de participação dos reassentados nas atividades desenvolvidas pelas Associações de Moradores, as informações demonstram que, quase a totalidade dos reassentados entrevistados afirmaram que participam das ações realizadas pelas associações, muitas vezes movidos pelo intuito de receber alguma forma de ajuda que esta possa proporcionar.

Tabela 8 - Participação nas atividades da associação dos moradores do reassentamento

\begin{tabular}{cc}
\hline Participação na Associação & $\%$ \\
\hline Participa & $95,08 \%$ \\
Não participa & $4,92 \%$ \\
\hline Fonte: Dados da pesquisa
\end{tabular}

A grande maioria dos reassentados $(95,08)$ afirmaram que a participação junto a essas associações é de extrema importância para o bom andamento de algumas ações realizadas pelas famílias dentro de seus lotes. É através das associações que muitos dos reassentados conseguem adquirir instrumentos e práticas para viabilizar muitas de suas atividades, como por exemplo: uso de implementos agrícolas na produção, orientações para plantios coletivos, aquisição de conhecimentos técnicos e práticos através dos cursos que são oferecidos, e assistência técnica especializada da EMATER e de outras entidades. Conforme Sigaud (1992), para que se produza uma boa coesão entre essas famílias parece ter sido decisivo o surgimento de associações no interior dos reassentamentos formados, que passaram a funcionar como grupos de pressão junto a diferentes organismos do Estado, no sentido de forçar a liberação de recursos para obras de infraestrutura, assim como para a obtenção de crédito.

O grau de participação dos reassentados nos casos analisados devem considerar inúmeras especificidades encontradas em cada uma dessas unidades. Observamos que muitas das associações são consideradas bem sucedidas por apresentarem pessoas confiáveis e responsáveis que as conduzem, e pelo alto grau de mobilização popular que essas áreas possuem, sobretudo quando são marcadas as reuniões para discutirem 0 andamento das diversas ações a serem 
implementadas. Contrariamente, em alguns casos, registra-se queixas por partes dos reassentados de má condução das atividades, que na maioria das vezes é atribuída a culpa ao presidente da associação.

Já quando nos referimos às questões culturais que envolvem a vida nesses novos lugares, o que se registra são perdas significativas no momento atual em relação à preservação da cultura de origem, seus costumes, suas práticas religiosas no interior do reassentamento. Muito pouco, no momento, é feito com relação ao assunto. Registra-se um distanciamento grande da Igreja Católica em relação aos reassentados, já que grande parte destes se declararam católicos. Ainda sim são realizadas algumas festas tradicionais, que movimentam bastante as comunidades, principalmente nas agrovilas que possuem maior quantidade de pessoas. Por exemplo: Festa do Bom Jesus no mês de agosto, no Povoado de Peixe Cru em Turmalina- MG. Fato essencial para que estas festividades tradicionais continuem existindo é que as identidades devem estar ancoradas ao sentimento de pertencimento a uma determinada localidade, e assim criar "[...] uma consciência de si na relação com o outro [...] "(CARNEIRO, 1998, p.13).

Conforme bem demonstrou Giddens (1990), nas sociedades tradicionais o passado é algo venerado e todas as simbologias são peças fundamentais para a perpetuação de tais experiências entre as gerações. A tradição aparece como uma forma de lidar com o tempo e o espaço, que então é estruturado pelas práticas sociais recorrentes.

\section{CONCLUSÃO}

O caso estudado traz à discussão a violência de que os empreendimentos hidrelétricos significam quando se observa a inevitabilidade do deslocamento, tendo em vista que este é um processo forçado. As grandes decisões estão nas mãos daqueles que detêm os critérios técnicos de atuação, ou seja, os grandes empreendedores, e o diálogo com a sociedade se dá somente quando quase tudo já está definido. $O$ que se observa nestes processos são meras formalidades que trazem caráter legitimador e de convencimento de que a obra é necessária e de que todos vão sair ganhando. Conforme foi descrito, os passos dados na trajetória de vida dos atingidos de Irapé revelam que pouca margem foi dada às possibilidades 
de mudanças e de adequação das necessidades dos reassentados, demonstrando que a possibilidade de reversão de determinadas situações são muito pequenas, a medida que não se pode mais voltar a morar aonde já está alagado.

Apesar de trazermos para essa discussão final a constatação de que algumas famílias atingidas se demonstraram felizes com suas atuais condições de vida, sobretudo devido à boa administração de seus recursos e suas terras, as barragens ainda são vistas, conforme apresenta Sigaud (1992), como se fosse algo temporário, significando apenas um susto na vida dos atingidos, em que a recuperação se dará de forma bem rápida diante de algumas medidas de mitigação e compensação que podem ser propostas. Neste ponto, elencamos novamente, a constatação da insatisfação de muitos daqueles que foram abordados pela pesquisa em relação à diversos aspectos que compreendem a vida individual e coletiva dessas populações. Os motivos de uma possível infelicidade, ou até mesmo o contrário, são bastante complexos; que podem variar desde as relações mais simples entre as pessoas e seus meios de vida de outrora, ou de relação com a natureza, que se tornaram essência para suas vidas; até mesmo devido à incorporação da mentalidade de que o homem de hoje só pode se realizar plenamente quando está inserido na dinâmica capitalista e dos benefícios que ela pode trazer.

Muito ainda está por se fazer neste percurso que é tão longo, na perspectiva de que os atingidos por barragens sejam reconhecidos em sua condição humana e cidadã, em que não pese somente os deveres mais como também o pleno exercício de seus direitos. Questionamos com um olhar crítico as visões que são atribuídas aos nossos rios de que são grandes jazidas de energia, prontas para gerarem riquezas. Ao passo que, do outro lado desconhece-se, ou mesmo força-se desconhecer, que os rios também são expressão territorial máxima na vida de muitas pessoas, servindo este como recurso essencial à condição de reprodução do homem e de todo acervo cultural que este constrói ao longo das gerações.

\section{BIBLIOGRAFIA}

ALVES FILHO, E. Legitimação de saberes dos trabalhadores rurais e sustentabilidade dos assentamentos de Minas Gerais. Departamento de Economia, Universidade Federal de Viçosa, Viçosa, Relatório de Pesquisa, 2008. 
CANDIDO, Antônio. Os parceiros do Rio Bonito: estudo sobre o caipira paulista e a transformação dos seus meios de vida. São Paulo. Livraria Duas Cidade, 2003

CARNEIRO, M. J. Ruralidade: novas identidades em construção. Estudos Sociedade e Agricultura. Rio de Janeiro, n. 11, 1998.

DURKHEIM, Émile \& MAUSS, Marcel. Algumas formas primitivas de classificação: contribuição para o estudo das representações coletivas. In: Ensaios de Sociologia. São Paulo. Perspectiva, 2ª Edição, 2001.

GIDDENS, Anthony. Consecuencias de la modernidad. Madrid: Alianza, 1990.

GOBO, Giampietro, O Projeto de pesquisa nas investigações qualitativas. In $\mathrm{MELUCCl}$, Alberto. Por uma sociologia reflexiva - Pesquisa qualitativa e cultura. Petrópolis: Vozes, 2005, p.91-115.

GODOY, A. S. Introdução à pesquisa qualitativa e suas possibilidades. In: Revista de Administração de Empresas. São Paulo: v.35, n.2, p. 57-63, abril 1995.

HEREDIA, Beatriz Maria Alasia de. A morada da vida: trabalho familiar de pequenos produtores do Nordeste do Brasil. Rio de Janeiro, Paz e Terra, 1979.

MELUCCI, Alberto. A invenção do presente - Movimentos Sociais nas Sociedades Complexas. Petrópolis/ RJ: Vozes, 2001.

REBUGHINI, Paola, (2005). A comparação qualitativa de objetos complexos e os efeitos da reflexibilidade. in MELUCCI, Alberto. Por uma sociologia reflexiva Pesquisa qualitativa e cultura. Petrópolis: Vozes, p.237-261.

RIBEIRO. E. M. ; GALIZONI, F. M. Água, população rural e políticas de gestão: O caso do Vale do Jequitinhonha, Minas Gerais. Revista Ambiente e Sociedade, Vol. V - no 2 - p. 129 - 146 jan./jul. 2003.

SANTOS, Sônia B. M. Lamento e Dor. Uma análise sócio-antropológica do deslocamento compulsório provocado pela construção de barragens. Tese de Doutorado. Programa de Pós-Graduação em Ciências Sociais. Universidade Federal do Pará/Université de Paris, 2007.

SIGAUD, Lygia. O efeito das tecnologias sobre as comunidades rurais: o caso das grandes barragens. RBCS, n.18, ano 7, 1992.

SOUZA, Amaury (Org.). Qualidade de vida urbana - Introducão, Rio de Janeiro: Zahar, 1982. (Debates Urbanos n. 7).

SPOSITO, Maria Encarnação Beltrão. Cidade e campo: Relações e contradições entre urbano e rural. São Paulo, Editora Expressão Popular, 2010 
VAINER, Carlos Bernardo. Regionalismo e projeto nacional: uma reflexão sobre regionalismos velhos e novos. Cadernos Ippur UFRJ, Rio de Janeiro, n.2, p. 21-34, 1993.

WANDERLEY, Maria de Nazareth Baudel. O mundo rural como espaço de vida: reflexos sobre a propriedade da terra, agricultura familiar e ruralidade. Porto Alegre: UFRGS Editora, 2009.

(Recebido em 19.09.2013. Aceito em 06.12.2013) 